Relations industrielles

Industrial Relations

\title{
Wage Problems in Japan, Ministry of Foreign Affairs and \\ Ministry of Labor, Tokyo, Japan, 1962, 26 pp.
}

\section{Jacques St-Laurent}

Volume 18, numéro 2, avril 1963

URI : https://id.erudit.org/iderudit/1021446ar

DOI : https://doi.org/10.7202/1021446ar

Aller au sommaire du numéro

Éditeur(s)

Département des relations industrielles de l’Université Laval

ISSN

0034-379X (imprimé)

1703-8138 (numérique)

Découvrir la revue

Citer ce compte rendu

St-Laurent, J. (1963). Compte rendu de [Wage Problems in Japan, Ministry of Foreign Affairs and Ministry of Labor, Tokyo, Japan, 1962, 26 pp.] Relations industrielles / Industrial Relations, 18(2), 287-287.

https://doi.org/10.7202/1021446ar

Tous droits réservés (C Département des relations industrielles de l’Université Laval, 1963
Ce document est protégé par la loi sur le droit d'auteur. L’utilisation des services d'Érudit (y compris la reproduction) est assujettie à sa politique d'utilisation que vous pouvez consulter en ligne.

https://apropos.erudit.org/fr/usagers/politique-dutilisation/ 
travailleurs déplacés de se caser ailleurs après une période de réadaptation plutôt brève. Il ne s'agit pas d'un problème de changement dans les structures de production qui irait de pair avec un processus général de substitution de capital au travail. Le problème est plutốt celui d'une allocation différente du travail et non pas d'un remplacement du facteur travail par d'autres facteurs de production. Pour cette raison, l'intérêt immédiat de l'étude pour le règlement des problèmes canadiens de l'emploi est moindre que ne le laisse entendre le titre.

Il reste cependant que les problèmes traités sont universels même s'ils ne se manifestent pas avec la même acuité partout ou même si, ailleurs, d'autres types de chômage sont plus importants. L'étude est partagée en deux: la première partie précise la nature des changements de structures dont il est question. La seconde suggère les mesures qui tendent à faciliter les ajustements. La prudence avec laquelle on a rédigé le titre de la seconde partie est significative: il ne s'agit pas de panacée. Il ne s'agit pas de mesures qui règleraient nécessairement les problèmes. Il s'agit de mesures qui tentent - non pas de les régler - mais d'en faciliter le règlement. Cela, à mon avis, souligne bien les difficultés énormes posées par la solution des problèmes soulevés à l'occasion d'un changement dans les structures. Ils sont complexes, mouvants et fuyants. Les gouvernements les plus honnêtes sont parfois dans l'impossibilité de les régler à la satisfaction, non pas de tous, mais du plus grand nombre.

L'étude n'envisage donc le problème du chômage devant l'évolution des structures que dans une certaine conjoncture et pour un certain type d'évolution. De plus, l'analyse se situe surtout au niveau de la micro-économique c'est-à-dire au niveau de l'entreprise, ou de l'industrie, même si on suggère des remèdes que l'Etat seul peut imposer.

Ces remarques ne sont pas faites dans le but de minimiser les qualités de l'étude puisqu'elle est excellente. Elles ne sont là que pour signaler les limites à l'intérieur desquelles elle est vraiment excellente.
Wage Problems in Japan, Ministry of Foreign Affairs and Ministry of Labor, Tokyo, Japan, 1962, 26 pp.

Sans fouiller à fond les problèmes de la rémunération des travailleurs au Japon, cette publication en présente avec beaucoup de clarté les caractéristiques principales. On y signale avec à-propos dans quelle mesure certaines exigences sociales conditionnent la façon dont fonctionne le marché du travail. Par exemple, dans la détermination des salaires, on accorde plus d'importance qu'ici à l'âge et aux années de service. Ce sont là des exigences imposées par la société et c'est à l'intérieur de ces unités que s'applique la théorie de la productivité marginale. A cause de ces exigences, la distribution des emplois se fait d'une façon passablement différente de la nôtre. D'ailleurs, même chez nous, l'importance relative de l'ancienneté comme critère de détermination des salaires prend une importance croissante. C'est là un phénomène que le processus d'automation tend à accélérer. Malgré l'introduction dans les conventions collectives de clauses d'ancienneté de plus en plus strictes, il ne semble pas cependant que cette dernière ait chez nous un rôle aussi déterminant qu'au Japon.

En plus de souligner certaines caractéristiques du salariat, la publication tente de corriger la réputation que l'on fait au Japon en disant que cest un pays où les salaires sont bas. C'est là un argument souventes fois utilisé par les producteurs étrangers afin d'inciter leurs propres pays à protéger par des tarifs ou des quotas le marché local devant el'invasion» des exportations japonaises. La publication signale que les salaires versés aux travailleurs des industries d'exportation majeures se comparent avantageusement à ceux versés aux travailleurs européens des mêmes industries. Ce serait le cas entr'autres de l'industrie de l'acier et celle de la construction navale. Dans le cas de l'industrie textile, et celle des jouets, les salaires plus bas s'expliqueraient par le fait que les travailleurs sont surtout des jeunes femmes et que les bénéfices marginaux y sont - comme partout ailleurs au Japon - relativement plus importants qu'en Amérique. 